Article

\title{
Radionuclide Transfer in the Zirconium Oxychloride Production Process and the Radiation Effect in a Typical Chinese Enterprise
}

\author{
Shoulong $\mathrm{Xu}^{1,2, *}$, Qifan $\mathrm{Wu}^{1, *}$, Xiaogang $\mathrm{Li}^{3}{ }^{3}$, Feng Yuan ${ }^{3}$ and Liangying $\mathrm{Tu}^{3}$ \\ 1 Department of Engineering Physics, Tsinghua University, Beijing 100084, China \\ 2 School of resource Environment and Safety Engineering, University of South China, Hengyang 421001, China \\ 3 Jiangxi Provincial Radiation Environment Supervision Station, Nanchang 330039, China; \\ 19110740037@fudan.edu.cn (X.L.); lyb@jxepb.gov.cn (F.Y.); lzxtly@163.com (L.T.) \\ * Correspondence: xushoulong@tsinghua.edu.cn (S.X.); wuqifan@tsinghua.edu.cn (Q.W.)
}

Received: 27 September 2019; Accepted: 23 October 2019; Published: 24 October 2019

check for updates

\begin{abstract}
The radiation impact on the environment from naturally-occurring radioactive materials in zircon sand is an important issue for zirconium product manufacturing enterprises. In this paper, a typical oxychloride production enterprise has been taken as an example to study the radiation effect and environmental pollution during the whole production process. The transfer and enrichment of radionuclides in zircon sand was studied by analyzing their concentrations in samples, such as products and wastes, which were sampled from every studied workshop, so that the dose rate in the environment and typical facility surfaces of each workshop could be measured. The study results show that the transfer and enrichment of radionuclides occur mainly in workshops of acidification, dissolution, concentration and crystallization. Silicon slag adsorbed some radionuclides, but most of the radionuclides in raw materials are transferred and enriched in waste acid by the concentration and crystallization process. Sludge and wastewater still contain a large quantity of radionuclides after treatment by wastewater treatment plants. This results in a significant increase in U-238 and Th-232 concentrations in river water near the main outlet. The average effective dose of all employees in the studied enterprises was $0.94 \mathrm{mSv}$, and workers from the wastewater treatment plants had the largest annual effective dose at $11 \mathrm{mSv}$.
\end{abstract}

Keywords: radionuclide transfer; radiation effect; zirconium oxychloride; zircon sand; monazite

\section{Introduction}

Zirconium oxychloride, as the basic raw material for zirconium metallurgy and chemical zirconium, is mainly produced by a chemical production process with zirconium sand [1]. Zirconium products are widely used as corrosion-resistant structural materials in many fields, such as the Petroleum, Chemical and Energy fields. The main raw material, zircon sand, is mostly imported (i.e., into China) at present [2]. However, the composition of monazite in zircon sand is rich in radionuclides, such as uranium, thorium and radium [3-8]. This makes radiation a safety issue in the production of zirconium products. There are two main kinds of zircon sand processing technology: Physical separation and chemical separation. The monazite in zircon sand can be separated by the physical method because of its weak magnetic characteristic. However, the naturally-occurring radioactive materials in zircon sand are transferred and enriched with the chemical separation process, and discharged into the environment in the form of wastewater or solid waste $[9,10]$.

Therefore, the radiation issues mainly occur in the zirconium oxychloride production process, resulting in a potential radiation health hazard to workers in zirconium oxychloride production enterprises [11,12]. The acid-alkali method is currently the most widely used chemical processing 
method in large-scale zirconium chemical production enterprises in China [13]. It is necessary to study the radionuclide transfer and radiation effect of zirconium oxychloride production enterprises, utilizing the acid-alkali method.

In this paper, we take a typical oxychloride production enterprise as an example, in order to study the radiation effect and environmental pollution during the whole process. We propose a method for investigating the radiation status of the typical enterprise first. The transfer and enrichment of radionuclides in zircon sand was studied by analyzing the concentration of samples, such as products and wastes, which were sampled from every workshop. We measured the dose rate in the environment and the typical facility surfaces of each workshop, and calculated the individual and collective effective doses for the workers.

\section{Investigation and Experimental Methods}

Zircon sand, sodium hydroxide, hydrochloric acid and water are the materials required for the acid-alkali zirconium oxychloride production method. $\mathrm{SiO}_{2}, \mathrm{ZrSiO}_{4}$ and monazite are the main components of zircon sand. Monazite is a rare-earth phosphate which demonstrates radioactivity. The radionuclides of monazite mainly exist in the form of $\mathrm{U}_{3} \mathrm{O}_{8}$ (the uranium compound oxide $\mathrm{UO}_{2} \mathrm{UO}_{3}$ ), $\mathrm{Th}_{3}\left(\mathrm{PO}_{4}\right)_{4}$ and $\mathrm{Ra}^{2+}$ (including phosphates and oxides of radium). Wastewater is generated in the workshops of alkali melting decomposition, washing and conversion, acidification and dissolution and extraction, and the wastewater contains sludge. Spent caustic liquid is generated from the washing and conversion process, and a waste acid solution is generated from the workshops undertaking concentration, crystallization and dehydration. The intermediate product in the process is sodium metasilicate pentahydrate, which is made by silicon slag, and the enterprise product is zirconium oxychloride. There are three waste treatment plants in the factory, which are used to treat the spent caustic liquid, silicon slag and waste acid solutions, respectively. A diagram of the process and the input and output materials is shown in Figure 1.

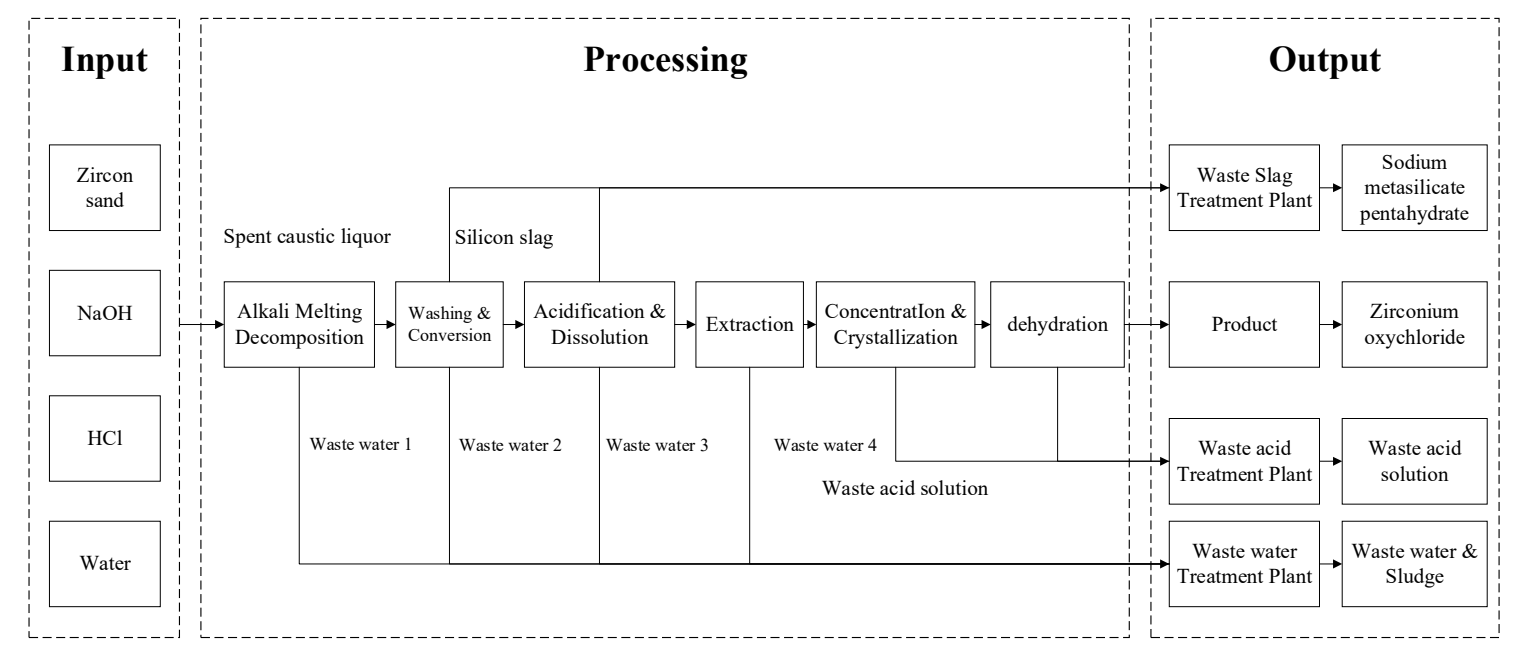

Figure 1. Diagram of the process and the input and output materials. The input raw materials are zircon sand, $\mathrm{NaOH}, \mathrm{HCl}$ and water, the intermediate product in the process is sodium metasilicate pentahydrate, and the enterprise product is zirconium oxychloride. The wastes are waste acid solution, spent caustic liquid, wastewater and sludge.

For this typical Chinese enterprise, the output of zirconium oxychloride is about $40,000 \mathrm{t} / \mathrm{a}$, and the consumption of zircon sand is about 24,000 t/a. The other raw materials, such as sodium hydroxide and hydrochloric acid, are about 29,200 t/a and 54,400 t/a, respectively. The volume of wastewater is about 1.4 million cubic meters per year, the output of solid waste (sludge) is 12,000 tons per year, and the output of wet silicon slag is 22,000 tons per year. 
Zircon sand is the only raw material, but this originates from different countries and places, and all the process links have their own discharged and produced products. There are intermediate products and waste treatment workshops in the enterprise. There are by-product workshops and waste treatment stations located in areas of the studied factory. Based on the amount of used raw materials and yielded products, the irradiation effect and the irradiation exposure of workers were investigated and studied by the methods of both sampling and detection. Samples are the raw materials, products, intermediate products, solid waste and liquid waste. Samples were measured by gamma spectrometers (HPGe) to analyze the radionuclide concentrations by measuring their gamma emitter daughters, $234 \mathrm{Th}(63 \mathrm{keV})$ for $238 \mathrm{U}, 214 \mathrm{Bi}(609 \mathrm{keV})$ for $226 \mathrm{Ra}$, and 228Ac (911.1 keV) for 232Th, respectively. Efficiency calibration and measurement were performed based on the China national standard (GB/T 11713-2015) of general analytical methods of high-purity germanium gamma spectrometers. The ICP-MS method (DZ/T 0064.80-1993) was used for measuring the $U$ and Th content in liquid. The gamma-ray radiation measurement was based on the workshops, and the workplace and the surfaces of the main facilities were detected using the FH40G + FHZ672E-10 nuclear radiation detector made by an American thermoelectric company. The radiation dose rate of the public environment in the factory was also detected.

\section{Radionuclides Transfer}

Almost all the radionuclides in this process come from zircon sand. The zircon sand of this enterprise is mainly imported (i.e., into China), and partly comes from Hainan. However, the concentrations of radioactive particles in the zircon sand from different batches and countries are obviously different. The activity concentration of radionuclides in the zircon sand are shown in Table 1. It can be seen from the analysis results of the activity concentration of radionuclides in this table that the activity concentration of U-238, Th-232 and Ra-226 in different batches of zircon sand is different, even among batches originating from the same place in the same country. The activity concentrations of the different radionuclides in zircon sand from Australia are basically the same, while the activity concentration of U-238 in zircon sand from South Africa is between 1.15 and $5.01 \mathrm{~Bq} / \mathrm{g}$, that of Th-232 is between 0.71 and $3.97 \mathrm{~Bq} / \mathrm{g}$, and that of Ra-226 is between 0.56 and $4.51 \mathrm{~Bq} / \mathrm{g}$. In the workshop for alkali melting decomposition, different batches of raw materials are usually mixed. Therefore, the average of the activity concentration of each type of radionuclide in the raw material has been estimated by averaging the analysis results in Table 1 ; that is, the average of the nuclide is used as the activity concentration of each nuclide in the raw material of the mixture. In this case, U-238 is 2.48 $\mathrm{Bq} / \mathrm{g}$, Th-232 is $1.52 \mathrm{~Bq} / \mathrm{g}$, and Ra-226 is $2.86 \mathrm{~Bq} / \mathrm{g}$.

Table 1. Activity concentrations of radionuclides in zircon sand (Bq/g).

\begin{tabular}{cccccccc}
\hline No. & Name & \multicolumn{2}{c}{ U-238 } & \multicolumn{2}{c}{ Th-232 } & Ra-226 \\
\hline 1 & $\begin{array}{c}\text { 1\# Zircon sand } \\
\text { From Australia }\end{array}$ & 3.99 & \pm 0.18 & 0.71 & \pm 0.03 & 3.72 & \pm 0.15 \\
\hline 2 & $\begin{array}{c}\text { 2\# Zircon sand } \\
\text { From Australia }\end{array}$ & 3.29 & \pm 0.42 & 0.55 & \pm 0.04 & 3.38 & \pm 0.20 \\
\hline 3 & $\begin{array}{c}\text { 1\# Zircon sand } \\
\text { From South Africa }\end{array}$ & 1.51 & \pm 0.07 & 0.83 & \pm 0.04 & 4.51 & \pm 0.18 \\
\hline 5 & $\begin{array}{c}\text { 2\# Zircon sand } \\
\text { From South Africa }\end{array}$ & 1.15 & \pm 0.05 & 3.97 & \pm 0.16 & 0.56 & \pm 0.03 \\
\hline 5 & $\begin{array}{c}\text { 3\# Zircon sand } \\
\text { From South Africa }\end{array}$ & 5.01 & \pm 0.52 & 0.57 & \pm 0.04 & 3.47 & \pm 0.21 \\
\hline $\begin{array}{l}\text { 3\# Zircon sand } \\
\text { From Kenya }\end{array}$ & 1.18 & \pm 0.05 & 3.44 & \pm 0.13 & 0.41 & \pm 0.02 \\
\hline $\begin{array}{c}\text { 3\# Zircon sand } \\
\text { From Hainan, China }\end{array}$ & 1.24 & \pm 0.06 & 0.59 & \pm 0.03 & 3.95 & \pm 0.16 \\
\hline
\end{tabular}


Table 2 shows the analysis result of the activity concentrations of radionuclides in products and other solid materials. The results show that the activity concentrations of U-238, Th-232 and Ra-226 in zirconium hydroxide are similar to those in zircon sand, indicating that radionuclides have not been transferred by alkali melting decomposition, washing, and the conversion processes. This is because the reaction of zircon sand with $\mathrm{NaOH}$ solution in the process of alkali melting decomposition mainly produces $\mathrm{Na}_{2} \mathrm{SiO}_{3}$ and $\mathrm{ZrSiO}_{4}$, which are all precipitates. After the reaction of radioactive material in zircon sand with $\mathrm{NaOH}$, the uranium, thorium and radium enter into the slurry as precipitates of hydroxide and sodium uranate. The chemical equations between the radionuclides and $\mathrm{NaOH}$ are shown as Formulas (1)-(4). The bottom slurry is filtered to form a filter cake. Zirconium silicate in the filter cake is transformed into zirconium hydroxide after adding hydrochloric acid, and the uranium, thorium and radium exist in the zirconium hydroxide as solids. This is why the concentrations of radionuclides in zirconium hydroxide are similar to those in zircon sand.

Table 2. Activity concentrations of radionuclides in in products and other solid materials (Bq/g).

\begin{tabular}{cccccccc}
\hline No. & Name & \multicolumn{2}{c}{ U-238 } & \multicolumn{2}{c}{ Th-232 } & \multicolumn{2}{c}{ Ra-226 } \\
\hline 1 & Zirconium hydroxide & 2.04 & \pm 0.24 & 3.36 & \pm 0.02 & 2.33 & \pm 0.14 \\
2 & Silicon slag & 1.47 & \pm 0.17 & 0.93 & \pm 0.06 & 0.066 & \pm 0.006 \\
3 & Zirconium oxychloride & $<0.01$ & - & $<0.003$ & - & 0.01 & \pm 0.001 \\
4 & Wet sludge after concentration & 44.83 & \pm 4.97 & 22.91 & \pm 1.41 & 19.36 & \pm 1.17 \\
5 & Sludge in wastewater treatment station & 6.23 & \pm 0.69 & 2.05 & \pm 0.13 & 1.21 & \pm 0.073 \\
\hline
\end{tabular}

$$
\begin{gathered}
\mathrm{Th}_{3}\left(\mathrm{PO}_{4}\right)_{4}+12 \mathrm{NaOH}=3 \mathrm{Th}(\mathrm{OH})_{4} \downarrow+4 \mathrm{Na}_{3} \mathrm{PO}_{4} \\
2 \mathrm{U}_{3} \mathrm{O}_{8}+\mathrm{O}_{2}+6 \mathrm{NaOH}=3 \mathrm{Na}_{2} \mathrm{U}_{2} \mathrm{O}_{7} \downarrow+3 \mathrm{H}_{2} \mathrm{O} \\
\mathrm{UO}_{2}+4 \mathrm{NaOH}=\mathrm{U}(\mathrm{OH})_{4} \downarrow+2 \mathrm{Na}_{2} \mathrm{O} \\
\mathrm{Ra}^{2+}+2 \mathrm{NaOH}=\mathrm{Ra}(\mathrm{OH})_{2} \downarrow+2 \mathrm{Na}^{+}
\end{gathered}
$$

We analyzed the radionuclide concentration in liquid waste effluents and process effluents by sampling the river water at the main outlet of the plant, the river at the upstream and downstream, the wastewater, the waste alkali liquid, and the waste acid liquid discharged from each workshop. It can be seen that the concentrations of U-238 and Th-232 in the environmental background were $1.6 \times$ $10^{-4}$ and $4.2 \times 10^{-5} \mathrm{mg} / \mathrm{L}$, respectively. The results of liquid water sample analysis in Table 3 show that the concentration of U-238 and Th-232 in the waste alkali liquid is lower than in the extraction wastewater and waste acid. As the concentration and crystallization cycles increase, the concentration of radionuclides in the waste acid increases obviously. In the third cycle waste acid liquid, the concentration of U-238 is about 10 million times higher than the background concentration, and that of Th-232 is 30 million times higher. The wastewater discharged from the main outlet of the enterprise increased the concentration of U-238 and Th-232 in the river by 4.04 times and 3.09 times, respectively. The radionuclide concentration decreased significantly due to the river water dilution, and was close to but slightly higher than the background level at $1.2 \mathrm{~km}$ downstream of the river. 
Table 3. Radionuclide concentrations in liquid waste effluents and process effluents (mg/L).

\begin{tabular}{ccccc}
\hline No. & Workshop & Sample Name & U & Th \\
\hline 1 & & 250 m upstream of the main outlet & $1.6 \times 10^{-4}$ & $4.2 \times 10^{-5}$ \\
2 & the main outlet & $7.1 \times 10^{-4}$ & $1.3 \times 10^{-4}$ \\
3 & River water & 180 m downstream of the main outlet & $2.7 \times 10^{-4}$ & $6.9 \times 10^{-5}$ \\
4 & & 1.2 km downstream of the main outlet & $2.1 \times 10^{-4}$ & $5.6 \times 10^{-5}$ \\
\hline 5 & & Dusting wastewater & $2.9 \times 10^{-1}$ & $3.97 \times$ \\
6 & Alkali Melting & Conversion wastewater & $5.2 \times 10^{-2}$ & $<2 \times 10^{-4}$ \\
7 & Washing \& Conversion & First cycle waste alkali liquid & $1.2 \times 10^{-1}$ & $7.2 \times 10^{-4}$ \\
8 & & Second cycle waste alkali liquid & $1.9 \times 10^{-2}$ & $3.5 \times 10^{-4}$ \\
\hline 9 & Acidification \& & Silicon Slag Compressed Wastewater & $6.6 \times 10^{-3}$ & $<2 \times 10^{-4}$ \\
10 & Dissolution & Slag washing wastewater & $1.1 \times 10^{-3}$ & $4.2 \times 10^{-3}$ \\
\hline 11 & Extraction & Extraction wastewater & $3.09 \times 10^{2}$ & $2.3 \times 10^{-3}$ \\
\hline 12 & Concentration \& & First cycle waste acid liquid & $2.14 \times 10^{2}$ & $1.55 \times 10^{2}$ \\
13 & Crystallization & Second cycle waste acid liquid & $2.48 \times 10^{2}$ & $1.85 \times 10^{2}$ \\
14 & & Third cycle waste acid liquid & $1.54 \times 10^{3}$ & $1.31 \times 10^{3}$ \\
\hline
\end{tabular}

In the acidification process, zirconium oxychloride and silicon slag are generated from the reaction between zirconium hydroxide and hydrochloric acid. Meanwhile, sodium uranate itself dissolves in acid. Therefore, the radionuclides are acidified and enter into the acid solution. The chemical reaction equations of the hydroxides of the radionuclides with hydrochloric acid are shown in Formulas (5)-(7). The activity concentration of U-238 and Th-226 in silicon slag is about $60 \%$ of that of zircon sand, but Ra-226 is about $2.3 \%$ of that of zircon sand, which indicates that silicon slag still adsorbed some part of the radionuclides after conversion.

The activity concentration value of radionuclides in zirconium oxychloride is very low, which indicates that concentration and crystallization can separate the radionuclides from the zirconium oxychloride and acid solution effectively. The activity concentration of radionuclides in sludge is very high, but after dewatering in the wastewater treatment plant, the activity concentration of all kinds of radionuclides decreases obviously, which indicates that the radionuclides in concentrated wet sludge are still mainly in the liquid. This is because radionuclides are dissolved into the waste acid in the form of acid solutes after acidification, and radionuclides are enriched in the waste acid after three cycles of concentration and crystallization. Therefore, in the process of chemical zirconium production, the radionuclides are mainly transferred to the waste acid.

$$
\begin{gathered}
\mathrm{Th}(\mathrm{OH})_{4}+4 \mathrm{HCl}=\mathrm{ThCl}_{4}+4 \mathrm{H}_{2} \mathrm{O} \\
\mathrm{U}(\mathrm{OH})_{4}+4 \mathrm{HCl}=\mathrm{UCl}_{4}+4 \mathrm{H}_{2} \mathrm{O} \\
\mathrm{Ra}(\mathrm{OH})_{2}+2 \mathrm{HCl}=\mathrm{RaCl}_{2}+2 \mathrm{H}_{2} \mathrm{O}
\end{gathered}
$$

In conclusion, there is no alkali liquid discharge in the process of alkali melting decomposition, so there is no transfer and enrichment of radionuclides. Radionuclides are in the zirconium hydroxide in the form of solid precipitates in the workshop of washing and conversion. Zirconium hydroxide is transformed into zirconium oxychloride in the process of acidification and dissolution. Radionuclides are dissolved into hydrochloric acid in the form of solutes, and some radionuclides are adsorbed by silica slag. Radionuclides are almost separated and left in the acid after concentration and crystallization. Therefore, for chemical zirconium processing with the acid-sodium metasilicate pentahydrate method, the radionuclides are mainly converted into precipitates in the alkali melting decomposition process 
and dissolved in hydrochloric acid in the acidification workshop. Some non-reactive substances in the zircon sand are precipitated in the form of sludge.

\section{External Dose Measurement and Dose Assessment}

The radiation dose rate of the main objects in the technological workshops are shown in Table 4. According to the previous analysis, radionuclides come from zircon sand. Before the concentration process, most radionuclides are transferred with the material. After the concentration process, the radionuclides are transferred into the acid solution. Therefore, the surfaces of facilities related to zircon sand and waste acid have a high radiation dose rate, which is consistent with the measured data in Table 3. As we can see from Table 4, the surface radiation dose rate of zircon sand is about $1.86 \mu \mathrm{Sv} / \mathrm{h}$. The surface radiation dose rate of silicon slag produced by the water-soluble processing is less than $0.26 \mu \mathrm{Sv} / \mathrm{h}$, and that of silicon slag storage and slag washing facilities is less than $0.2 \mu \mathrm{Sv} / \mathrm{h}$. This shows that the material and thickness of the container wall attenuate radioactivity to a certain extent, even if the silicon slag contains radionuclides. The average surface dose rate of zirconium oxychloride is about $0.3 \mu \mathrm{Sv} / \mathrm{h}$, which indicates that there is also a small amount of radionuclides in the product. According to the results in Table 2, the radioactivity of zirconium oxychloride mainly comes from the decay of Ra-226. The surface dose of the main facilities in the concentration and crystallization workshops is relatively large, especially on the surface of the filter press for the waste acid concentration and the waste acid storage tank. The maximum surface dose rate of the filter press is $2.24 \mu \mathrm{Sv} / \mathrm{h}$, which is caused by the contamination of waste acid in the filter press. The waste acid storage tank is mainly used to store second cycle waste acid liquid. The maximum surface dose rate is $17.2 \mu \mathrm{Sv} / \mathrm{h}$. In the workshops for acidification, radionuclides are enriched in acid, resulting in a higher level of radioactivity on the surface of the acid storage containers. The waste acid transfer tank in wastewater treatment plants is an intermediate storage facility, which is used to transfer the third cycle waste acid to the waste acid treatment plant.

Table 4. External dose rate near materials or in workshops (nSv/h).

\begin{tabular}{|c|c|c|c|c|c|c|}
\hline No. & Workshops & Target & Min & Max & Mean & Deviation \\
\hline 1 & $\begin{array}{c}\text { Product } \\
\text { warehouse }\end{array}$ & Packaged products & 291 & 320 & 302 & 9 \\
\hline 2 & \multirow{4}{*}{$\begin{array}{l}\text { Wastewater } \\
\text { Disposal }\end{array}$} & Wastewater storage tank & 790 & 1110 & 947 & 147 \\
\hline 3 & & Waste acid transfer tank & 25,000 & 29,200 & 27,320 & 1564 \\
\hline 4 & & Reaction tank & 583 & 602 & 595 & 9 \\
\hline 5 & & PH regulating tank & 865 & 874 & 870 & 4 \\
\hline 6 & \multirow{4}{*}{ Waste repository } & Doorway & 1120 & 1180 & 1152 & 20 \\
\hline 7 & & Inside & 4660 & 6230 & 5028 & 549 \\
\hline 8 & & Outside & 391 & 406 & 400 & 5 \\
\hline 9 & & Dry sludge & 3710 & 4220 & 3993 & 196 \\
\hline 10 & $\begin{array}{l}\text { Raw Material } \\
\text { Warehouse }\end{array}$ & Zircon Sand & 1790 & 1990 & 1864 & 67 \\
\hline 11 & \multirow{2}{*}{$\begin{array}{c}\text { Burning \& } \\
\text { Washing \& } \\
\text { Conversion }\end{array}$} & Feed port & 1070 & 1170 & 1120 & 50 \\
\hline 12 & & $\begin{array}{c}\text { Filter press } \\
\text { (Zirconium hydroxide) }\end{array}$ & 122 & 212 & 160 & 38 \\
\hline 13 & \multirow{3}{*}{$\begin{array}{l}\text { Acidification \& } \\
\text { Dissolution }\end{array}$} & Silicon slag storage tank & 100 & 119 & 111 & 8 \\
\hline 14 & & Slag washing tank & 160 & 185 & 173 & 10 \\
\hline 15 & & silicon slag & 250 & 260 & 256 & 3 \\
\hline 16 & \multirow{5}{*}{$\begin{array}{l}\text { Concentration \& } \\
\text { Crystallization }\end{array}$} & Crystallizer barrel & 92 & 169 & 140 & 29 \\
\hline 17 & & $\begin{array}{c}\text { Filter press } \\
\text { (Second cycle waste acid) }\end{array}$ & 1330 & 2240 & 1864 & 420 \\
\hline 18 & & Concentrated waste acid storage tank & 16,500 & 18,000 & 17,200 & 587 \\
\hline 19 & & Zirconium oxychloride product outlet & 77.4 & 77.6 & 77.5 & 0.1 \\
\hline 20 & & Stacked products & 68.0 & 702 & 385 & 317 \\
\hline
\end{tabular}


According to the analysis results of the water samples shown in Table 3, the concentration of uranium and thorium in the waste acid of the third cycle is much higher than that of the second cycle. The surface dose of the third cycle waste acid storage tank has the maximum level of radioactivity in the plant area, at $27.3 \mu \mathrm{Sv} / \mathrm{h}$. The wastewater from workshops is stored in storage tanks and treated in reaction tanks and $\mathrm{pH}$ regulating tanks. The dose rate on the surface of the water treatment facilities is greater than $0.5 \mu \mathrm{Sv} / \mathrm{h}$. According to the analysis results in Table 3, the radionuclides in the wastewater mainly come from the wastewater discharged from the extraction workshop. The solid wastes are treated by the wastewater treatment workshop and transported to the waste repository for temporary storage. The maximum radiation dose rate inside the waste repository is over $5 \mu \mathrm{Sv} / \mathrm{h}$. After shielding by a shielding wall, the outside area with the maximum radiation dose rate is located at the entrance of the repository, with an average of $1.15 \mu \mathrm{Sv} / \mathrm{h}$. The radiation level outside the shielding wall is reduced to $0.4 \mu \mathrm{Sv} / \mathrm{h}$.

There are 14 main workshops in the factory area. Table 5 shows the radiation dose rate of the operator working areas in these workshops. We can see from the detection results in the table that zircon sand stored in the raw material warehouse has a high level of radioactivity. However, the distribution of the dose rate in the warehouse is uneven. This is due to the different raw material sources and locations of zircon sand. In the alkali melting decomposition workshop, the areas with high radioactivity levels are mainly located beside the feeding barrel, but the temperature of the alkali melting decomposition furnace is very high, and workers operate the facilities from a greater distance. Workers are exposed to a low dose of radiation in the workshops for washing, conversion, acidification and dissolution. This is because these processes are automated, and there is a certain distance between workers and facilities. However, in the concentration and crystallization workshop, radionuclides are mainly concentrated into the waste acid, therefore the dose rate on the surface of the waste acid storage tank is higher than that of the other facilities. The maximum value of the dose rate is detected beside the wet sludge with waste acid in the wastewater treatment plant. This detected result is consistent with the radionuclide enrichment workshop result shown in Table 3.

Table 5. External dose rate in operator working areas (nSv/h).

\begin{tabular}{cccccc}
\hline No. & Workshops & Min & Max & Mean & Deviation \\
\hline 1 & Raw Material Warehouse & 716 & 1990 & 1258 & 560 \\
2 & Alkali Melting Decomposition & 197 & 1400 & 776 & 430 \\
3 & Washing \& Conversion & 122 & 402 & 191 & 7 \\
5 & Acidification & 92 & 290 & 155 & 59 \\
6 & Dissolution & 90 & 280 & 157 & 57 \\
7 & Concentration & 68 & 702 & 155 & 120 \\
8 & Crystallization & 112 & 1290 & 675 & 410 \\
9 & Wastewater Disposal & 212 & 29,200 & 5294 & 8350 \\
10 & Waste Repository & 391 & 6960 & 3360 & 2620 \\
11 & Office & 86 & 108 & 96.6 & 9.2 \\
12 & Waste Slag Treatment Plant & 67 & 206 & 135 & 68 \\
13 & Wastewater Treatment Plant & 474 & 7210 & 3061 & 2620 \\
14 & Public area & 52 & 14,700 & 528 & 2030 \\
\hline
\end{tabular}

As we can see from Figure 1, the waste slag treatment plant receives the waste alkali liquor and the silica slag from the washing and conversion process, and the wastewater treatment plant receives the wastewater from all of the workshops. Meanwhile, the hydroxides of those radionuclides in zircon sand are insoluble in alkali solutions, but soluble in acid, and a certain amount of radionuclides will be adsorbed by silicon slag. Therefore, the dose rate in some areas of the waste slag treatment plant is slightly higher than the environmental background, and the dose rate in the waste water treatment plant is very high.

The maximum value of the dose rate in the public area of the factory is $14.7 \mu \mathrm{Sv} / \mathrm{h}$. The hot spots were detected on the surface of the pipeline on the west side of the concentration and crystallization 
workshop, which is used to transport the waste acid to the waste acid treatment plant. The dose rate in the office area is slightly higher than the background value, which indicates that there is no major contamination in the office.

Table 6 shows the collective and individual effective dose of workers in the workshops. There are 345 employees in the enterprise, including 187 workers in the workshop and 158 staff in the office. Employees work for $8 \mathrm{~h}$ a day, and the annual standard working hours are $2080 \mathrm{~h}$. The estimated results show that the average annual effective dose of all workers is about $0.94 \mathrm{mSv}$. The annual effective dose of workers who are working in the raw material storehouse, alkali melting decomposition workshop, crystallization workshop, and waste repository is over $1 \mathrm{mSv}$, especially among those in the waste repository, where the annual effective dose is $11.01 \mathrm{mSv}$. This value does not exceed the limit value of $20 \mathrm{mSv} / \mathrm{a}$, but it is still recommended to optimize the working time of workers who are in the workshops with a dose rate over $1 \mathrm{mSv}$, and therefore, radiation protection measures should be taken.

Table 6. Collective and individual effective doses of workers in workshops.

\begin{tabular}{ccccc}
\hline No. & Workshop & Number of Workers & $\begin{array}{c}\text { Collective } \\
\text { Person·mSv/a }\end{array}$ & $\begin{array}{c}\text { Individual Effective } \\
\text { (mSv/a) }\end{array}$ \\
\hline 1 & Raw Material Warehouse & 1 & 2.62 & 2.62 \\
2 & Alkali Melting & 30 & 48.4 & 1.61 \\
3 & Decomposition & 33 & 13.1 & 0.40 \\
4 & Washing \& Conversion & 12 & 3.87 & 0.32 \\
5 & Acidification & 33 & 10.8 & 0.33 \\
6 & Dissolution & 20 & 6.45 & 0.32 \\
7 & Concentration & 45 & 63.2 & 1.4 \\
8 & Crystallization & 13 & 143 & 11 \\
9 & Waste Repository & 158 & 31.8 & 0.20 \\
\hline
\end{tabular}

\section{Conclusions}

In this paper, we studied the radionuclide transfer and radiation effect of workshops used in the zirconium oxychloride production process with the acid-alkali method. The transfer and enrichment of radionuclides occur mainly in the workshops of acidification, dissolution, concentration and crystallization. Some amount of radionuclides is transferred to the by-product silicon slag in the washing and conversion workshop, and sent to the waste slag treatment plant for processing and reproduction. Most of the radionuclides in the raw materials are transferred and enriched in the waste acid by the concentration and crystallization process. After the third crystallization cycle, radionuclides are enriched in the third cycle waste acid and transported to the waste acid treatment plant for reproduction. This results in a high level of radioactivity in the waste acid treatment plant. The sludge and wastewater still contain a good deal of radionuclides after treatment by the wastewater treatment plant. This results in a significant increase of the U-238 and Th-232 concentration in the river water near the main outlet.

The maximum value of the dose rate in the factory area is $29.2 \mu \mathrm{Sv} / \mathrm{h}$, detected on the surface of the wastewater disposal. The radiation detection result indicates that the areas in the factory with high radioactivity levels are mainly distributed in the workshops for raw material storage, alkali melting decomposition, concentration, crystallization and wastewater treatment. The effective dose of workers in these workshops is over $1 \mathrm{mSv}$, especially for the workers in the water waste treatment plant, who have the largest annual effective dose at $11 \mathrm{mSv}$. Radiation protection measures should be taken, and the working time of these workers should be optimized.

Author Contributions: Conceptualization, S.X. and Q.W.; Methodology, Q.W. and S.X.; Validation, F.Y., L.T. and X.L.; Formal analysis, S.X.; Investigation, S.X. and Q.W.; Resources, X.L., L.T. and F.Y.; Data curation, S.X.; Writing—original draft preparation, S.X.; Writing—review and editing, Q.W.; Supervision, Q.W.; Project administration, Q.W.; Funding acquisition, Q.W. 
Funding: This research was funded by the National Natural Science Foundation of China (Project No. 11905102 and Project No. 61601423).

Acknowledgments: The authors would like to express their sincere gratitude to the Jiangxi Provincial Radiation Environment Supervision Station and Nanchang Environmental Protection Bureau for investigation assistance. This work was supported by the State Bureau of Nuclear Safety and the Ministry of Ecology and Environment of the Peoples' republic of China. The sample analysis was undertaken by the Beijing Research Institute of Uranium Geology.

Conflicts of Interest: The authors declare no conflict of interest.

\section{References}

1. Guo, S.J.; Dong, X.P. Zirconia Material Balance of Zirconium Oxychloride Production. Jiangxi Chem. Ind. 2014, 4, 119-121.

2. Li, Y.; Guo, K.; Lian, B. Research on Current Situation of Radiation Environmental Management of Zircon Industries in China. Environ. Sci. Manag. 2019, 44, 5-8.

3. Anonymous. Radiation protection aspects of the use of zircon sand. National Group for studying radiological implications in the use of Zircon Sand. Sci. Total Environ. 1985, 45, 135-142.

4. Viruthagiri, G.; Rajamannan, B.; Jawahar, K.S. Radioactivity and Associated Radiation Hazards in Ceramic Raw Materials and End Products. Radiat. Prot. Dosim. 2013, 157, 383-391. [CrossRef] [PubMed]

5. Righi, S.; Andretta, M.; Bruzzi, L. Assessment of the Radiological Impacts of a Zircon Sand Processing Plant. J. Environ. Radioact. 2005, 82, 237-250. [CrossRef] [PubMed]

6. Xing, F.H.; Fu, Y.F.; Yang, X.X.; Bi, J.J. The Radioactive Level of Processing Enterprises in a Zirconium-titanium Sand in Hainan Province Investigation and Analysis. Guangdong Chem. Ind. 2017, 44, 72-73.

7. Turhan, Ş.; Arıkan, İ.; Demirel, H.; Güngörc, N. Radiometric Analysis of Raw Materials and End Products in the Turkish Ceramics Industry. Radiat. Phys. Chem. 2011, 80, 620-625. [CrossRef]

8. Guo, Q.L.; Wang, Y.; Li, X.J. Radionuclide transport and radiation protection in production process of $\mathrm{ZrOCl}_{2}$ from zircon sand in a factor. Radiat. Prot. 2018, 38, 32-38.

9. Li, Y.; Jiang, D.M.; Huang, S.M. Environmental Supervision of Radioactive Waste Water Release during Zirconium Oxychloride Production. Titanium 2019, 36, 49-53.

10. Luo, X.W.; Luo, F.C.; Wu, J. Disposal craft and development trend of the production process of zirconium oxychloride. Mater. China 2009, 28, 62-64.

11. Li, Y.; Jiang, D.M.; Huang, S.M. Research on NORM Management in the Exploitation and Utilization of Zircon. Titanium 2017, 34, 14-18.

12. Zhao, L.B.; Liu, X.B.; Zhao, W.T. Analysis on radiation environment of a zircon sand dressing and processing enterprise. Environ. Dev. 2019, 31, 21-22.

13. Guo, S.J.; Dong, X.P. Acid-Alkali method zirconium oxychloride technology progress. Jiangxi Chem. Ind. 2013, 1, 28-31.

(C) 2019 by the authors. Licensee MDPI, Basel, Switzerland. This article is an open access article distributed under the terms and conditions of the Creative Commons Attribution (CC BY) license (http://creativecommons.org/licenses/by/4.0/). 